\title{
因HAD
}

DOI: http://doi.org/10.22585/hospdomic.v1i4.32

\section{Reseña de libro: Treinta y seis años al frente de una revista científica}

\section{Book review: Thirty-six years editing a scientific journal}

Helena Martín-Rodero

Biblioteca, Facultad de Medicina, Universidad de Salamanca, Salamanca, España.

\section{Correspondencia/Correspondence}

Helena Martín-Rodero. Universidad de Salamanca, Salamanca, España.

helena@usal.es

Conflicto de Intereses/Competing interest

No existe ningún conflicto de interés en el presente estudio

Ficha editorial

- Título: Treinta y seis años al frente de una revista científica: Memorias del director de Nutrición Hospitalaria

- Autor: Jesús Manuel Culebras Fernández

- Editorial: Universidad de León, Servicio de Publicaciones

- Número de páginas: 321 páginas

- ISBN: 978-84-9773-895-8

Copyright (c) Universidad de León

Copyright (C) Jesús Manuel Culebras Fernández

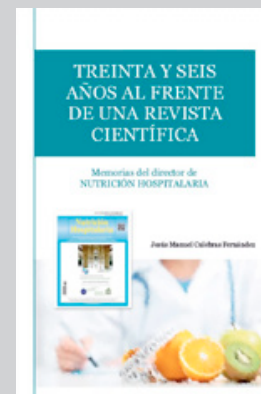

CÓMO CITAR ESTE TRABAJO | HOW TO CITE THIS PAPER

Martín-Rodero H. Reseña de libro: Treinta y seis años al frente de una revista científica. Hosp Domic. $2017 ; 1(4): 221-22$ 
El libro que aquí ven resume 36 años de la vida de un hombre singular, Jesús Culebras (Madrid 1946), médico-cirujano, referente en el campo de la nutrición hospitalaria y la edición científica en España. Hombre culto, visionario y soñador, ameno en el trato y gran conversador. Esto último es importante para entender que la obra que tenemos en las manos no es sólo un 'libro para especialistas', útil para documentalistas, bibliómetras, nutricionistas, historiadores de la ciencia o editores científicos, sino que es además un libro entretenido, ilustrado con anécdotas, vivencias y reflexiones del autor, aderezadas por los comentarios de aquellos que tuvieron la ocasión de conocerle y compartir con él esos años de su vida y de su sueño al frente de la revista 'Nutrición Hospitalaria'.

En el año 1979 comienza la andadura del proyecto como boletín de la Sociedad Española de Nutrición Parenteral y Enteral (SENPE). Apenas transcurridos 11 años, en 1990, el boletín, que ya se había transformado en la revista 'Nutrición Hospitalaria', mereció ser indexado en Index Medicus y en la base de datos MEDLINE. Años después de esta primera hazaña, vino la segunda, su incorporación a la Web of Science y su inclusión en el Journal Citation Reports (JCR).

El libro a través de sus 321 páginas ofrece una visión general de los inicios de la nutrición parenteral y de la creación de las primeras sociedades científicas en el ámbito de la nutrición en España, es el caso de la Sociedad Española de Nutrición Parenteral y Enteral (SENPE) fundada en 1977.

Asistimos a un recorrido personal y crítico por la investigación en nuestro país, mostrando el largo camino seguido por las publicaciones científicas en España y en español para hacerse un hueco en el panorama internacional, copado por las publicaciones en lengua inglesa, empresa entonces difícil y que, a día de hoy, continúa siendo una tarea ardua.

A través de la historia de «Nutrición Hospitalaria» hemos conocido cómo se han ido creado y desarrollando algunas de las más importantes bases de datos bibliográficas y plataformas de revistas científicas, cómo han surgido nuevos modelos de edición; el avance y consolidación, no exenta de crítica, de los índices de referencia internacional y la utilización de los indicadores bibliométricos como elementos indiscutibles en los procesos de evaluación de la ciencia y, por supuesto, el desarrollo de la propia investigación en nutrición a través de los artículos publicados en la revista durante este período de tiempo.

El libro cuenta con dos prólogos, el primero escrito por Abelardo García de Lorenzo y Mateos y el segundo por Miguel León Sanz en colaboración con José Manuel Moreno Villares, investigadores todos ellos, de referencia en el campo de la nutrición.

Finaliza el libro con los recuerdos y palabras de aquellos que compartieron profesión, intereses y vida con el autor.

Un libro interesante, enriquecedor y esencial para comprender el mundo de la edición científica en España y un libro ameno gracias a la claridad expositiva del autor cuya narración ha sabido hilvanar de manera sobresaliente. 